\title{
Gap Junction Channel Modulates Pulmonary Vascular Permeability through Calcium in Acute Lung Injury: An Experimental Study
}

\author{
Jinzhou Zhang ${ }^{a}$ Wen Wang ${ }^{b}$ Jing Sun ${ }^{c}$ Qiang Li $i^{a, d}$ Jincheng Liu ${ }^{a}$ \\ Hailong Zhu ${ }^{a}$ Tao Chen ${ }^{a}$ Hongbing Wang ${ }^{a}$ Shiqiang $\mathrm{Yu}^{\mathrm{a}}$ Guocheng Sun $^{\mathrm{a}}$ \\ Wensheng Chen ${ }^{\mathrm{a}}$ Dinghua $\mathrm{Yi}^{\mathrm{a}}$ \\ Departments of a Cardiovascular Surgery and ${ }^{\mathrm{b}}$ Traditional Chinese Medicine, and ${ }^{\mathrm{C}}$ Nursing Department, \\ Xijing Hospital, Fourth Military Medical University, Xi'an, and ${ }^{\mathrm{d} D e p a r t m e n t}$ of Cardiothoracic Surgery, \\ Second Affiliated Hospital, Shanxi Medical University, Taiyuan, People's Republic of China
}

\section{Key Words}

Acute lung injury • Gap junction channel • Gunshot injury • Pulmonary permeability · Thoracic wound

\begin{abstract}
Background: Increased pulmonary vascular permeability is a hallmark of acute lung injury (ALI). Gap junction channels (GJCs) connect adjacent cells and facilitate ion exchange. It remained unclear whether GJCs modulate pulmonary permeability in ALI through intracellular calcium. Objectives: This study aimed to verify if GJCs in pulmonary microvessel endothelial cells (PMVECs) modulate pulmonary vascular permeability in ALI via intracellular calcium. Methods: Firstly, an animal model of ALI was studied using connexin 40 (Cx40) inmunohistochemistry in the lung with Evans' blue (EB) leakage. Then cultured PMVECs were divided into three groups: $G_{\text {control, }} G_{\text {serum }}$ and $G_{\text {blocker }}$. Serum was obtained from animals with ALI following gunshot injury (injured serum). Initially, $G_{\text {blocker }}$ was treated with the blocker of GJCs, and then $G_{\text {serum }}$ and $G_{\text {blocker }}$ were stimulated with the injured serum, respectively. GJCs, the permeability of cell monolayers and intracellular $\mathrm{Ca}^{2+}$ were assessed. Results: $\mathrm{Cx} 40$ time-dependently decreased, whereas EB leakage increased. Cx40 and EB leakage exhibited a strong inverse correlation ( $\rho=$
\end{abstract}

-0.934, p < 0.05). Injured serum decreased GJCs and expression of $\mathrm{Cx} 40$, whereas the blocker aggravated this effect. Similarly, when PMVEC monolayer was treated with injured serum, both permeability and intracellular $\mathrm{Ca}^{2+}$ increased. These effects were also aggravated with the blocker. Conclusions: Depression of GJCs of PMVECs increased pulmonary vascular permeability in ALI; this effect may be mediated by the overload of intracellular calcium.

Copyright $\odot 2010$ S. Karger AG, Basel

\section{Introduction}

Acute lung injury (ALI) is a common, costly and potentially lethal disease, for which treatment of the underlying cause is the first step to recovery [1]. Many clinical and experimental studies have established the concept that increased-permeability pulmonary edema is the primary physiologic abnormality in the early stages of ALI

J.Z., W.W. and J.S. contributed equally to this work. The study was supported by the National Natural Science Foundation of China (No. 30801129) and Scientific \& Technological Projects of the Shaanxi Province [2007K13-03(2)].

\section{KARGER}

Fax +4161306 1234 E-Mail karger@karger.ch www.karger.com
(C) 2010 S. Karger AG, Base

$0025-7931 / 10 / 0803-0236 \$ 26.00 / 0$

Accessible online at:

www.karger.com/res
Wensheng Chen and Dinghua Yi, Department of Cardiovascular Surgery

Xijing Hospital, Fourth Military Medical University

Xi'an 710032 (People's Republic of China)

Tel. +86298477 1022, Fax +862983210092

E-Mail yidh@fmmu.edu.cn 
[2]. Thus, increased-permeability edema, defined as accumulation of protein-rich edema fluid in the alveoli, has become a hallmark of ALI [3], and modulating pulmonary permeability has become an important strategy to prevent and treat ALI.

Many studies have been performed to define the mechanisms that account for the acute increase in pulmonary vascular permeability in ALI [4]. The integrity of pulmonary microvessel endothelial cells (PMVECs) is a critical requirement for the preservation of pulmonary function [5]. PMVECs function as a semipermeable cellular barrier between the vascular and interstitial compartments; the general consensus is that fluid, macromolecules and leukocytes are transported through a PMVEC monolayer to the interstitial and subsequently the alveolar air spaces via the paracellular route. The essential role of paracellular transport in endothelial permeability has been supported by a substantial body of research, including electron-microscopic studies [5-7]. Garcia and Schaphorst [8] reported that the formation of the paracellular gap between endothelial cells (ECs) is regulated by a balance of competing contractile forces, which generate centripetal tension, and adhesive cell-cell and cell-matrix tethering forces, which together regulate cell shape changes. During this process, a key event that promotes $\mathrm{EC}$ contraction is the phosphorylation of regulatory myosin light chains catalyzed by $\mathrm{Ca}^{2+} /$ calmodulin-dependent myosin light chain kinase [5].

Gap junction channels (GJCs) connect the cytoplasm between adjacent cells to allow rapid exchange of ions and metabolites up to approximately $1 \mathrm{kDa}$ in size, including second messengers such as cyclic AMP, inositol triphosphate, and $\mathrm{Ca}^{2+}$. The crucial contribution of GJCs to disease etiopathology has been the subject of intensive research in recent years $[9,10]$, and connexin $40(\mathrm{Cx} 40)$ has been identified as the critical component of GJCs in ECs [11]. An abundance of data has proven the necessity of GJC communication to coordinate vascular behaviors during blood flow regulation, while $\mathrm{Cx} 40$-dependent coupling is necessary to regulate vascular behaviors and peripheral resistance [12]. Recent research revealed that thrombin inhibited intercellular calcium wave propagation in corneal ECs by modulation of hemi-channels and GJCs [13].

Based on the previous findings, we postulated that GJCs in PMVECs modulate pulmonary vascular permeability in ALI via intracellular calcium. Here, we first correlated the $\mathrm{Cx} 40$ level with pulmonary vascular permeability after ALI induced by thoracic gunshot wounds. Then the effects of a GJC blocker on the stimulation of
PMVECs by serum acquired from rabbits subjected to ALI were studied to determine the possible use of GJCs as a novel therapeutic target for the treatment of ALI.

\section{Materials and Methods}

\section{Animal Experiments}

All animal experiments were in accordance with the National Institutes of Health Guide for the Care and Use of Laboratory Animals and were approved by the Ethics Committee of the Fourth Military Medical University. All surgeries were performed in designated veterinary surgical suites using sterile instruments and procedures. Healthy, White New Zealand rabbits (weighing 2-3.1 kg, Experimental Animal Center, Fourth Military Medical University) were randomly assigned to one of the following five groups ( $n=8$ in each group) irrespective of gender: before (or sham-operated group; the interventions were the same as in the other groups except for gunshot injury) and 6, 12, 24 and $48 \mathrm{~h}$ after gunshot injury.

ALI was induced in the animals as described previously [14]. After shooting, first-aid treatment was immediately started, including closing of wounds, management of hemopneumothorax with thoracentesis and control of bleeding. Fluid was infused as needed to compensate for blood loss and to maintain systolic blood pressure $\geq 90 \mathrm{~mm} \mathrm{Hg}$. Normal saline was used depending on the bleeding rate. In ALI-surviving animals, a Swan-Ganz catheter was inserted through the right jugular vein to measure pulmonary artery wedge pressure excluding cardiogenic edema [15]. When pulmonary artery wedge pressure was $>2.6 \mathrm{~mm} \mathrm{Hg}$, the animal was excluded from the following investigations [16].

Arterial blood was sampled before and 6, 12, 24 and $48 \mathrm{~h}$ after gunshot injury. Analyses done immediately included arterial blood gases, hemoglobin and electrolytes. Blood samples for later analysis were obtained at the same time points. Serum values of the early cytokines TNF- $\alpha$ and IL- 8 were determined with standard kits by radioimmunoassay (Byk \& DiaSorin Diagnostics). For the stimulation in the ex vivo study, serum was obtained $12 \mathrm{~h}$ after gunshot injury (serum $12 \mathrm{~h}$ ). Furthermore, control serum was taken from rabbits before gunshot injury.

At each time point, 4 animals were killed with an overdose of anesthetic, the lungs were isolated, the trachea and bilateral bronchus were excised, and part of the left lung was removed, immediately weighed, left overnight in an oven at $110^{\circ} \mathrm{C}$ and again weighed to compute the wet/dry weight ratio. At the same time, part of the right lung tissue was sampled $2 \mathrm{~cm}$ away from the wound site for immunohistochemistry. The other 4 animals were selected to assess microvascular permeability of the lung tissue using Evans blue (EB) dye leakage.

\section{Immunohistochemistry}

Cryosections ( $5 \mu \mathrm{m}$ thick) were fixed and incubated with $0.2 \%$ BSA-C (Aurion) followed by incubation with primary antibodies for $1 \mathrm{~h}$. Biotin-SP-conjugated AffiniPure mouse anti-rabbit IgG (Dianova) and secondary antibodies were incubated at a dilution of 1:200 for $1 \mathrm{~h}$. The sections were covered and then viewed with a microscope (H600L, Nikon). Further documentation and image analysis were performed in a blinded fashion using a digital camera (DXM1200F, Nikon) and image processing software (ACT-1 
2.63, Nikon). Immunostaining of $\mathrm{Cx} 40$ was performed with Image-Pro Plus 5.0.

\section{Isolation of PMVECs and Primary Cell Culture}

PMVECs were isolated and cultured using a modified method described by Stevens et al. [17]. Cultured primary EC colonies were isolated, trypsinized, resuspended, seeded and then grown at $37^{\circ} \mathrm{C}$ with $5 \% \mathrm{CO}_{2}$ for $\sim 2-3$ days. Eventually, the primary PMVECs grew together into a slab-like continuous monolayer. Cells were characterized using anti-factor VIII by immunocytochemistry (Sigma).

PMVECs were divided into the following groups: control $\left(G_{\text {control }}\right)$, injured serum $\left(G_{\text {serum }}\right)$ and blocker agent $\left(G_{\text {blocker }}\right)$, that were all incubated in DMEM initially. In $\mathrm{G}_{\text {blocker }}$, the blocking agent (1-heptanol; $0.5 \mathrm{mM}$ ) was added to the medium for $1 \mathrm{~h}$. In $G_{\text {serum }}$ and $G_{\text {blocker }}$, cells were stimulated with serum $m_{12}$ h, i.e. $20 \%$ FBS was replaced by the same amount of serum $12 \mathrm{~h} . \mathrm{G}_{\text {control }}$ cells underwent the same procedures except for blocker and serum $\mathrm{m}_{12} \mathrm{~h}$ treatments.

\section{Scrape-Loading and Dye Transfer Technique}

A dye transfer assay was used to evaluate gap junction communication. PMVECs were rinsed with $2 \mathrm{ml}$ PBS. Two milliliters of $0.075 \%$ Lucifer yellow CH (molecular weight 443 Da, L-0259, Sigma) dissolved in PBS were added to the cells, and two scrape lines (parallel, equidistant scrapes per well) were made by gently passing a diamond-tipped pen (tip diameter $0.25 \mathrm{~mm}$ ) across the cultures. Subsequently, cells were examined with an inverted confocal microscope (FV1000 IX81, Olympus) at emission/excitation wavelengths of $528 / 425 \mathrm{~nm}$. Images were quantified by counting the number of donor and recipient cells and calculating a cell coupling index with the ratio of recipient to donor cells. The value of dye transfer, defined as the number of secondary recipient cells visualized by Lucifer yellow $\mathrm{CH}$, was recorded for only one side of the scrape.

\section{Measurement of Monolayer Endothelial Permeability}

PMVEC permeability was assessed by EB-labeled albumin transfer, as previously described [18]. Clearance of EB albumin was measured up to $90 \mathrm{~min}$. Measurements of transendothelial albumin flux are expressed as the percentage of clearance of bovine serum albumin compared with untreated controls.

\section{Western Blot}

Expression levels of $\mathrm{Cx} 40$ and their phosphorylated isoforms were measured by Western blotting in PMVECs. Cells were washed with PBS and lysed in buffer. After centrifugation, the supernatant was collected and protein content was quantified using the bicinchoninic acid protein assay (Pierce) in comparison to albumin standards. To measure signal intensity, blots were covered with enhanced chemiluminescence reagents (Amersham Biosciences) for $5 \mathrm{~min}$ and then exposed to film. $\beta$-Actin expression was used as internal standard.

\section{Measurement of Intracellular $\mathrm{Ca}^{2+}$}

The concentration of intracellular $\mathrm{Ca}^{2+}$ was measured with Fluo-3 acetoxymethyl ester (Fluo-3 AM, 50013, Biotium). InterVision software was used to calculate the value of $\left[\mathrm{Ca}^{2+}\right]_{\mathrm{i}}$ in selected regions from the changes in fluorescence of the Fluo-3 indicator according to the following equation: $\left[\mathrm{Ca}^{2+}\right]_{\mathrm{i}}=\mathrm{K}_{\mathrm{d}} \times\left(\mathrm{F}-\mathrm{F}_{\min }\right) /$
$\left(\mathrm{F}_{\max }-\mathrm{F}\right)$, where $\mathrm{F}_{\max }$ is maximum fluorescence and $\mathrm{F}_{\min }$ minimum fluorescence. The $\mathrm{K}_{\mathrm{d}}$ value for calcium binding to Fluo-3 is $450 \mathrm{nM}$ at $25^{\circ} \mathrm{C}$.

Intracellular free $\mathrm{Ca}^{2+}$ concentration changes were estimated as $\Delta F / F 0$, where $\Delta F$ is the fluorescence intensity of the response minus the baseline intensity and $F 0$ was derived from the averaged intensity of the first 10-20 frames minus the background in the cell-free region. Cells that changed fluorescence intensity $>10 \%$ over the course of an experiment were eliminated from further analysis.

\section{Statistical Analysis}

Statistical analysis was performed with SPSS 14.0 for Windows. Numeric variables are expressed as means \pm SD. Comparisons among experimental conditions were performed using one- or two-way ANOVA if the variables depended on time. The Bonferroni post-test was performed to determine significant differences between experimental conditions. Probability values $<0.05$ were considered statistically significant. The Pearson's correlation test was used to analyze EB permeability and optical density (OD) of $\mathrm{Cx} 40$.

\section{Results}

\section{General Conditions and Laboratory Examination}

Fifteen rabbits were killed instantly or within $2 \mathrm{~h}$ and excluded from the experiment. At autopsy, there was abundant hemorrhage in the pleural cavity, 4 showed rupture of the right branch of the pulmonary artery, 3 ruptures of the right ventricular anterior wall, 3 hemorrhages in the superior right lung lobe, 2 thoracic spinal column fractures with inferior caval vein rupture, 2 intercostal vessel hemorrhages and 1 cervical vertebral fracture.

The oxygenation index $\left(\mathrm{PaO}_{2} / \mathrm{FiO}_{2} ; \mathrm{mm} \mathrm{Hg}\right)$ decreased after injury, being $<300 \mathrm{~mm} \mathrm{Hg} 12 \mathrm{~h}$ after injury $\left(\mathrm{PaO}_{2} /\right.$ $\mathrm{FiO}_{2}, 385 \pm 22,342 \pm 19,283 \pm 25,227 \pm 16$ and 184 \pm 21 , fig. 1a). The chest radiograph taken $12 \mathrm{~h}$ after gunshot injury revealed rib fractures and diffuse bilateral infiltrates (fig. 1b).

\section{Serum Concentrations of TNF- $\alpha$ and IL-8}

Surviving $(\mathrm{n}=32)$ and sham-operated rabbits $(\mathrm{n}=8)$ received the following treatments. TNF- $\alpha$ and IL- 8 concentrations were significantly higher $6,12,24$ and $48 \mathrm{~h}$ after than before gunshot injury (TNF- $\alpha, 0.505 \pm 0.071$, $0.927 \pm 0.134,1.006 \pm 0.097,0.646 \pm 0.083$ vs. $0.236 \pm$ 0.049, fig. 2a; IL-8, $5.32 \pm 0.44,5.9 \pm 1.12,5.64 \pm 0.71$, $5.29 \pm 0.96$ vs. $3.81 \pm 0.28$, fig. $2 b ; p<0.05$ ). In all groups, the lung water content (wet/dry ratio) was significantly higher after compared with before gunshot injury $(5.50 \pm 1.03,9.27 \pm 1.77,7.73 \pm 1.59,8.13 \pm 2.01$ vs. $4.13 \pm 0.92$, fig. 2 c; $p<0.05$ ). 

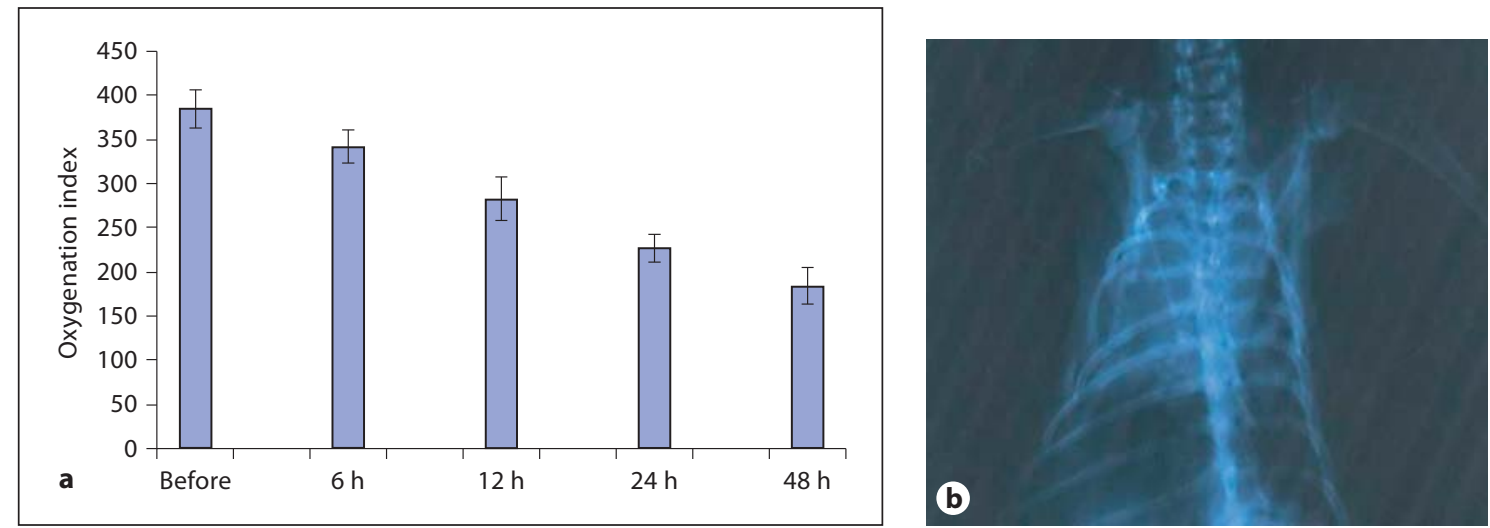

Fig. 1. a Oxygenation index before and after gunshot injury. b Rib fractures and diffuse bilateral infiltrates were seen on the chest radiograph taken $12 \mathrm{~h}$ after gunshot injury.
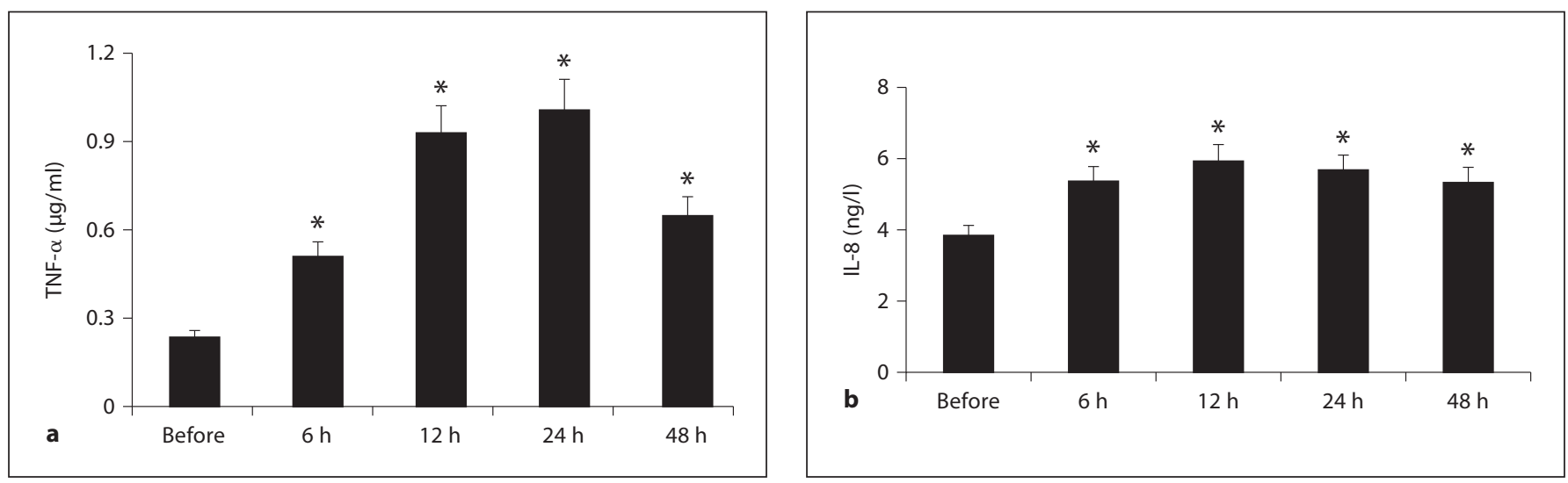

Fig. 2. a TNF- $\alpha$ concentration at different times after gunshot injury. IL-8 concentration (b) and water content (c) significantly increased after gunshot injury $\left({ }^{*} \mathrm{p}<0.05\right)$.

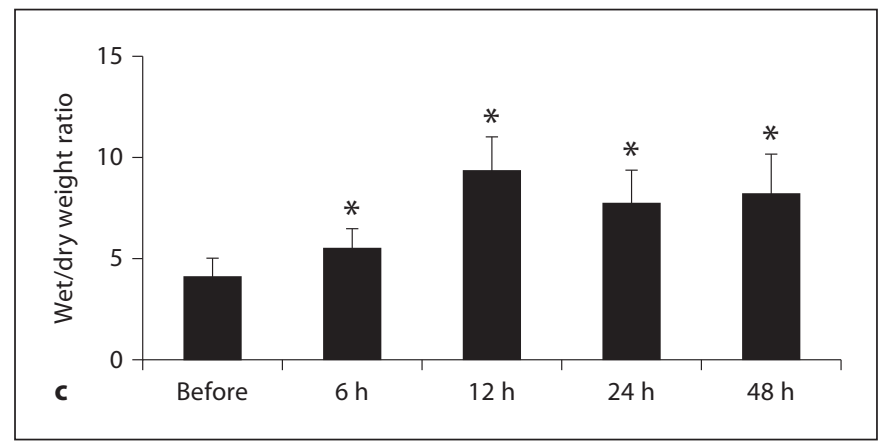

Cx40 Level and EB Leakage in Injured Lung Tissue

Immunostaining with $\mathrm{Cx} 40$ antibodies was observed throughout the pulmonary EC membrane. The mean OD values of $\mathrm{Cx} 40$ staining (fig. 3f) decreased after gunshot injury [176.20 \pm 25.34 (fig. 3a) vs. $160.34 \pm 16.34$ (fig. 3b), $134.42 \pm 8.12$ (fig. 3c), $118.83 \pm 12.95$ (fig. $3 \mathrm{~d}$ ) and 92.19 \pm 16.34 (fig. $3 \mathrm{e} ; \mathrm{p}<0.05$ ) before vs. $6,12,24$ and $48 \mathrm{~h}$ after gunshot injury, respectively].

EB leakage rates from lung tissue time-dependently increased after gunshot injury $(12.02 \pm 3.19$ vs. $26.76 \pm$ $5.77,67.62 \pm 11.36,53.56 \pm 17.94$ and $81.69 \pm 16.58$, before vs. $6,12,24$ and $48 \mathrm{~h}$ after gunshot injury, respec- 

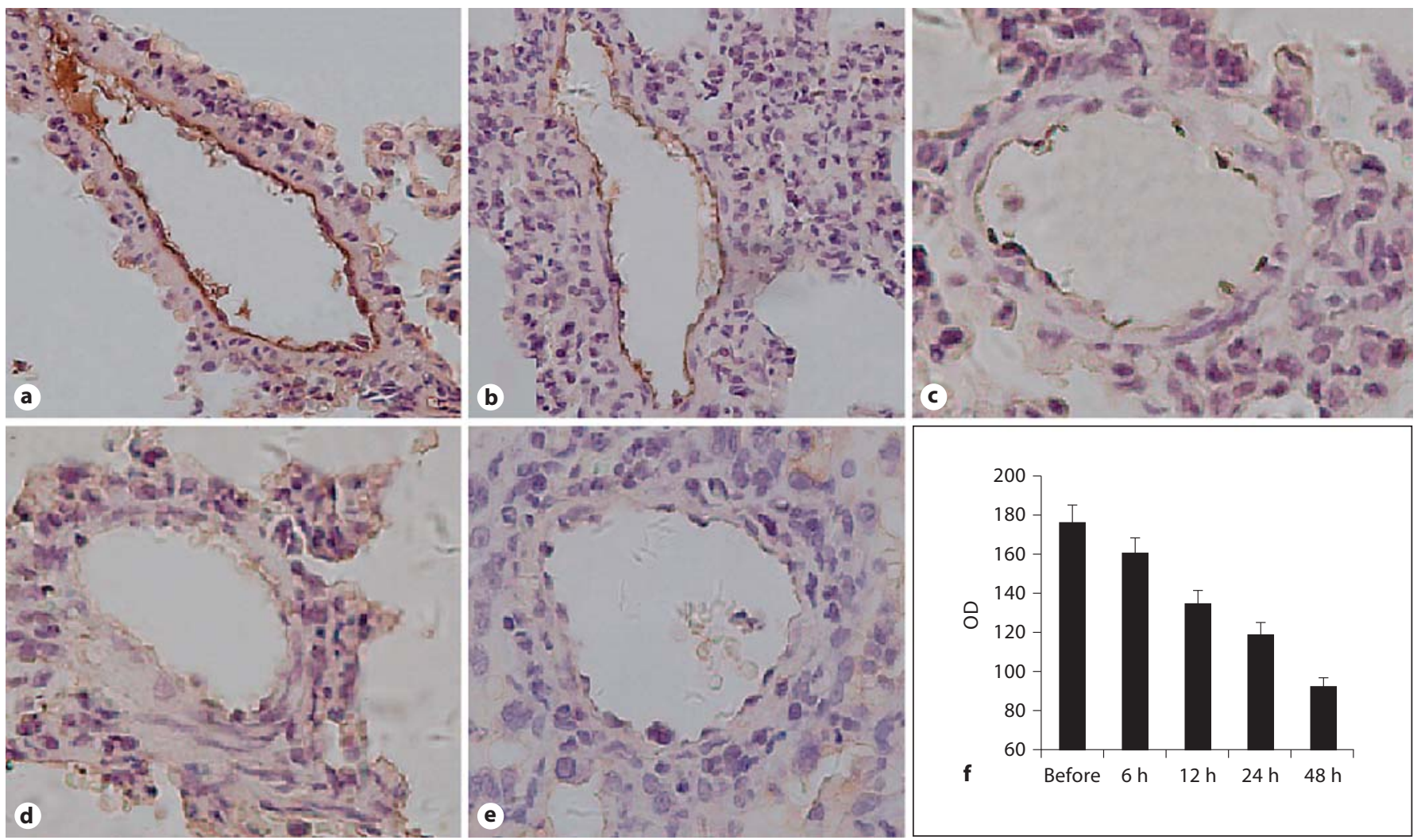

Fig. 3. Immunohistochemistry for $\mathrm{Cx} 40$ showed staining in pulmonary EC membranes before (a), and 6 (b), 12 (c), 24 (d) and $48 \mathrm{~h}$ (e) after gunshot injury. Original magnification, $\times 400$. f OD values significantly decreased with time.

tively; $\mathrm{p}<0.05$; fig. $4 \mathrm{a})$. There was also a significant negative correlation between the EB leakage rates and OD values $\left(\rho=-0.934, p<0.05, \rho^{2}=0.8723\right.$; fig. $\left.4 b\right)$, i.e., a higher $\mathrm{Cx} 40$ level was correlated with less leakage from the pulmonary capillary bed.

\section{Dye Transfer}

Similar cell numbers were initially loaded with dye in all treatment groups (fig. 5). However, fewer neighboring cells were labeled with $\mathrm{G}_{\text {serum }}$ (fig. 5b) and $\mathrm{G}_{\text {blocker }}$ (fig. 5c), with the lowest count occurring after $\mathrm{G}_{\text {blocker }}$ treatment. The recipient/donor cell ratios of $G_{\text {control }}$ (fig. 5a), $G_{\text {serum }}$ and $G_{\text {blocker were }} 23 \pm 5,11 \pm 3$ and $7 \pm 2$, respectively (p $<0.05$; fig. $5 \mathrm{~d})$.

\section{PMVEC Permeability Assay}

Treatment with serum and a gap junction blocker time-dependently increased PMVEC permeability (twoway ANOVA). There are significant increases in the clearance ratio compared with baseline $(60,90$ or $30 \mathrm{~min})$ both in $\mathrm{G}_{\text {serum }}(170 \pm 28 \%, 210 \pm 30 \%$ vs. $105 \pm 21 \%, \mathrm{p}<$ $0.05)$ and $G_{\text {blocker }}(185 \pm 29 \%, 240 \pm 35 \%$ vs. $105 \pm 19 \%$, $\mathrm{p}<0.05$; fig. 6$)$.

\section{Western Blot}

PMVECs grown in injured medium for $2 \mathrm{~h}$ exhibited reduced $\mathrm{Cx} 40$ level (fig. 7a). In cells grown in the three media, $\mathrm{Cx} 40$ protein level was reduced by injured serum and blocker conditions $(54.78 \pm 15 \%$ and $43.68 \pm 13 \%$ of control, $\mathrm{p}<0.05$; fig. $7 \mathrm{~b})$.

\section{Intracellular $\mathrm{Ca}^{2+}$ Concentration}

The three groups of PMVECs loaded with Fluo-3 were imaged on an inverted confocal microscope, and fluorescence intensity was higher in $\mathrm{G}_{\text {serum }}$ and $\mathrm{G}_{\text {blocker }}$ than in $\mathrm{G}_{\text {control }}$. Thus, the concentrations of intracellular $\mathrm{Ca}^{2+}$ in PMVECs in the $G_{\text {serum }}$ and $G_{\text {blocker }}$ groups were higher than in the $\mathrm{G}_{\text {control }}$ group $(494.8 \pm 41.94,569.8 \pm 6.70$ vs. $158.8 \pm 13.09 \mathrm{nM}$, respectively, $\mathrm{p}<0.05$; fig. 8,9 ). 

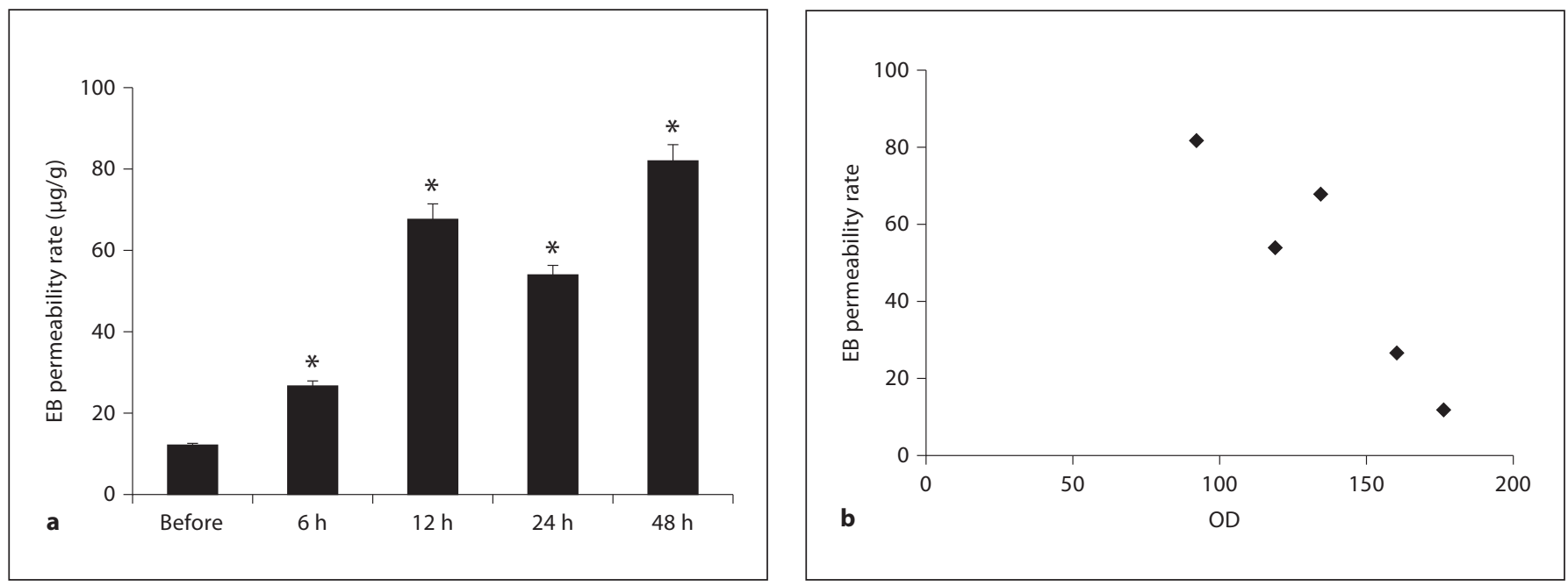

Fig. 4. a EB leakage from lung tissues after gunshot injury $\left({ }^{*} \mathrm{p}<0.05\right)$. b There was a significant, negative correlation between OD values and EB permeability rates $(\rho=-0.934, \mathrm{p}<0.05)$, with a correlation coefficient $\left(\rho^{2}\right)$ of 0.8723 .
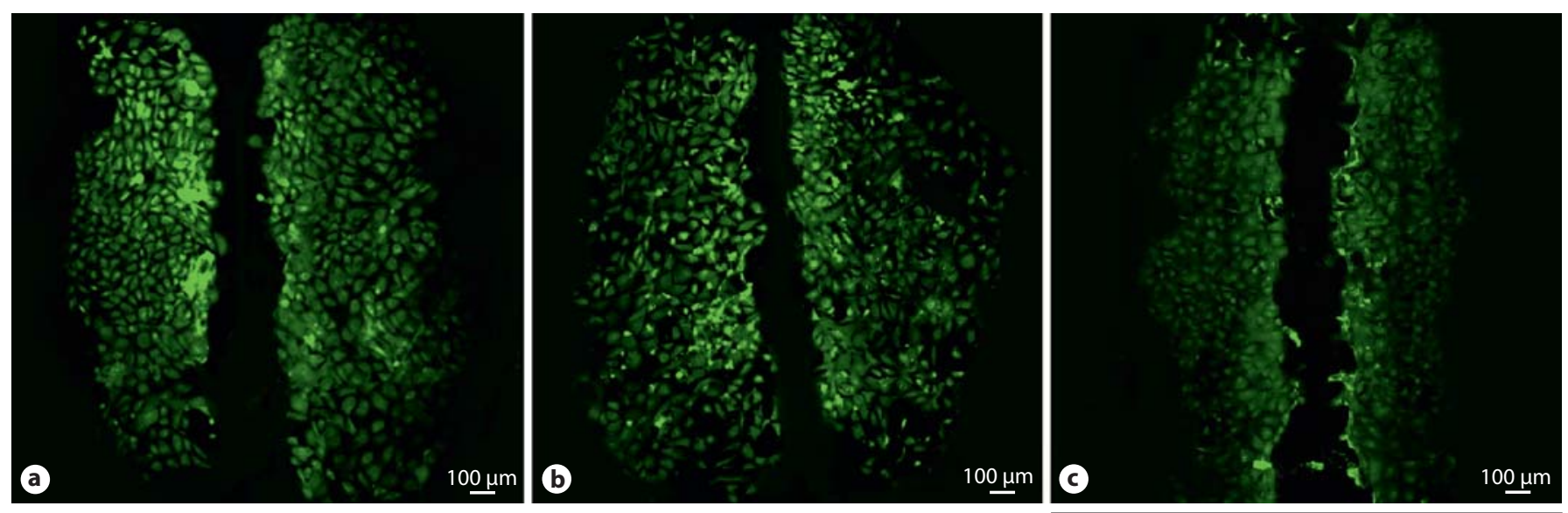

Fig. 5. Dye transfer in ECs on slides; a region of ECs scrape-loaded with dye is shown. a $G_{\text {control }}$. b $G_{\text {serum. }}$ c $G_{\text {blocker }}$ (Green indicates Lucifer yellow, including cells initially loaded with dye and recipient cells linked to the donors by gap junctions.) d Quantification of dye transfer in $\mathrm{G}_{\text {control}}, \mathrm{G}_{\text {serum }}$ and $\mathrm{G}_{\text {blocker }}\left({ }^{*} \mathrm{p}<0.05\right)$.

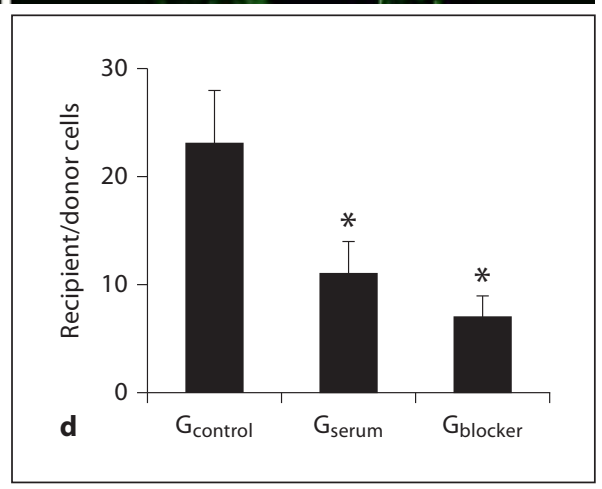



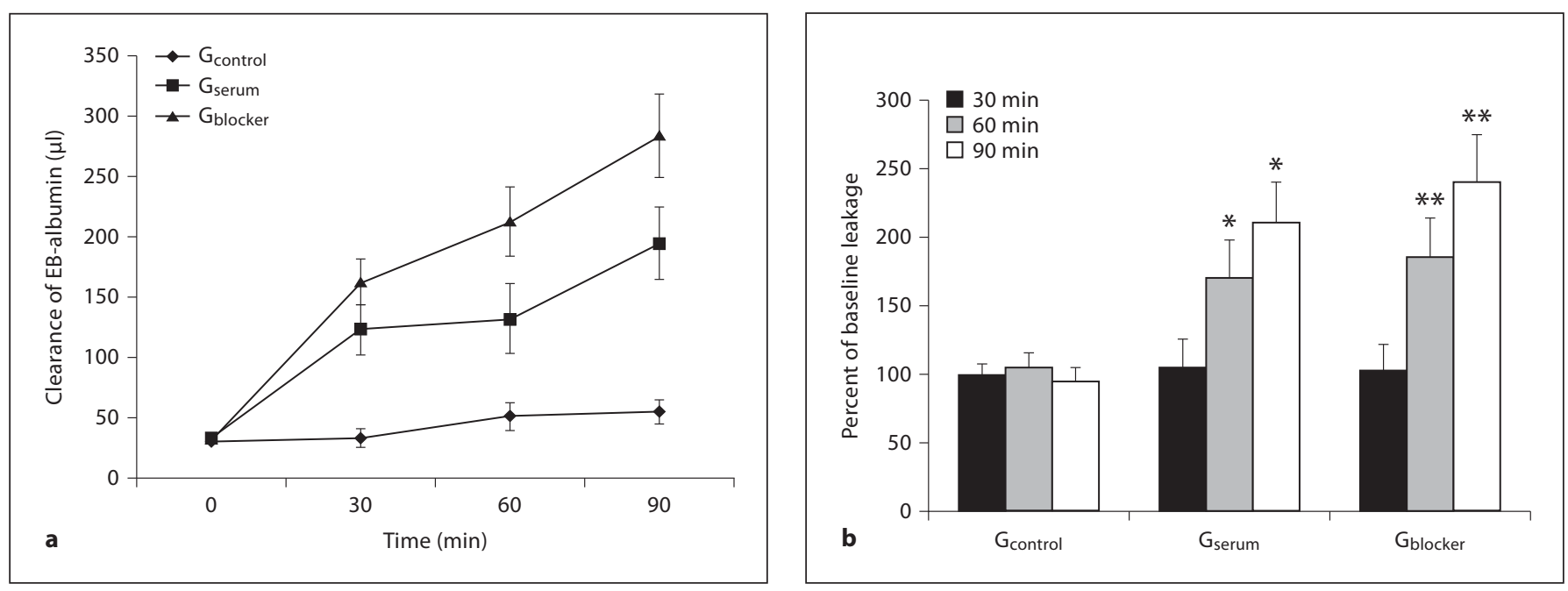

Fig. 6. $G_{\text {serum }}$ and $G_{\text {blocker }}$ treatment significantly increased PMVEC permeability compared with $G_{\text {control. }}$ a EBalbumin clearance. b Clearance ratio compared with baseline. ${ }^{*} \mathrm{p}<0.05,60$ and $90 \mathrm{~min}$ or $30 \mathrm{~min}\left(\mathrm{G}_{\text {serum }}\right)$, ** $\mathrm{p}<0.05,60$ and 90 min vs. $30 \mathrm{~min}\left(\mathrm{G}_{\text {blocker }}\right)$.
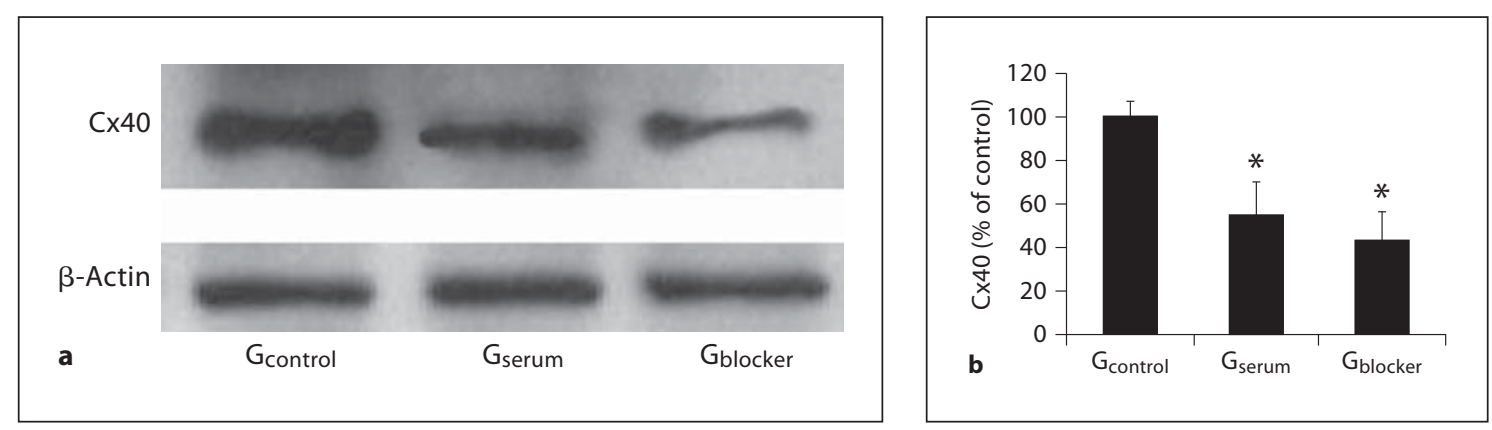

Fig. 7. a Western blot bands of $C x 40$ protein levels in PMVECs in $G_{\text {control }}, G_{\text {serum }}$ and $G_{\text {blocker }}$ b Cx40 protein levels in PMVECs grown in the three groups. Protein expression was significantly decreased in $G_{\text {serum }}$ and $\mathrm{G}_{\text {blocker }}$ compared with $\left.\mathrm{G}_{\text {control }}{ }^{*} \mathrm{p}<0.05\right)$.

\section{Discussion}

Thoracic gunshot injury decreased $\mathrm{Cx} 40$ level and increased pulmonary vascular permeability, with a significant correlation between Cx40 staining intensity and vascular permeability. Stimulation of PMVECs with serum $_{12} \mathrm{~h}$ decreased Cx40 levels and GJC function but increased PMVEC monolayer permeability, especially following treatment with a gap junction blocker. Furthermore, intracellular free calcium concentration increased. These effects were aggravated when a GJC blocker was added to the PMVECs prior to serum $\mathrm{m}_{12 \mathrm{~h}}$ treatment. Thus, these findings indicate that GJCs of PMVECs modulate pulmonary vascular permeability following thoracic gunshot injury, contributing to the development of ALI possibly via changes in intracellular calcium. This is the first study to elucidate the relationship between GJC function and pulmonary vascular permeability, and the results suggest that GJCs might provide a novel therapeutic target for the treatment of lung inflammation, including ALI.

Though various factors lead to the occurrence of ALI [19-21], severe trauma is still a major cause of ALI. In a study by Treggiari et al. [22], the incidence of ALI was $4-12 \%$ in 1,296 patients who survived $24 \mathrm{~h}$ or more after trauma. We previously established an animal model of 

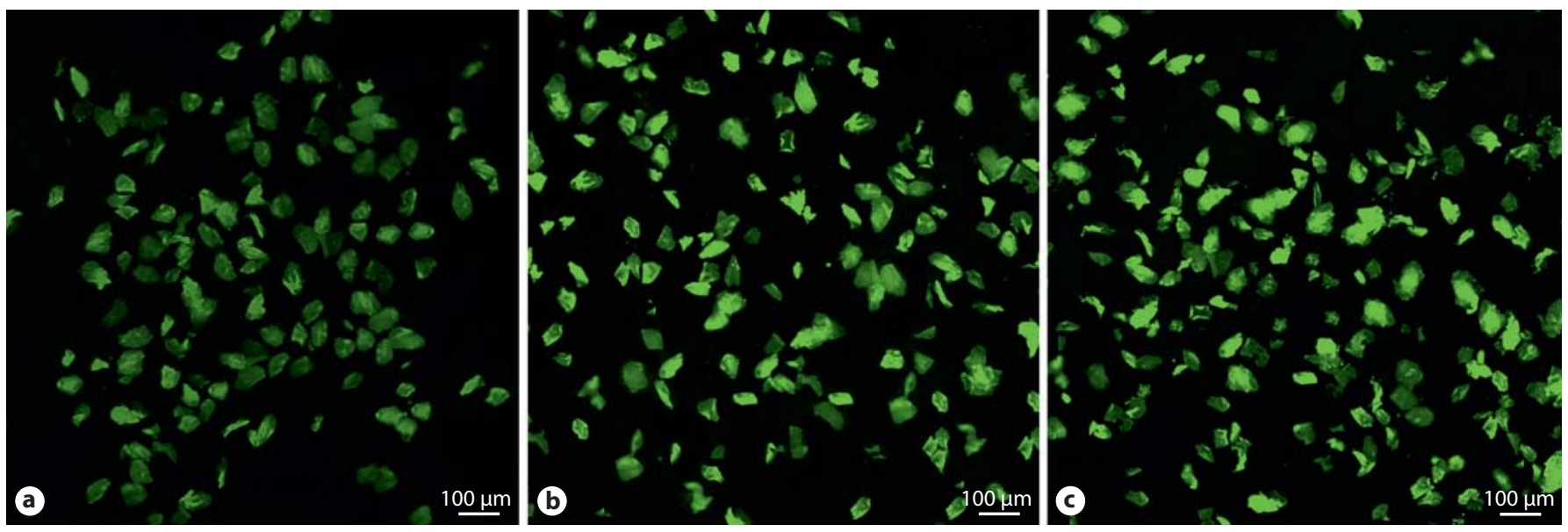

Fig. 8. Images from the three groups of PMVECs $30 \mathrm{~s}$ after excitation. a $G_{\text {control }}$. b $G_{\text {serum }}$. c $G_{\text {blocker. The fluo- }}$ rescence intensity was higher in $\mathrm{G}_{\text {serum }}$ and $\mathrm{G}_{\text {blocker }}$ than in $\mathrm{G}_{\text {control }}$. Thus, the $\left[\mathrm{Ca}^{2+}\right]_{\mathrm{i}}$ concentration in PMVECs was higher in $\mathrm{G}_{\text {serum }}(494.8 \pm 41.94 \mathrm{nM})$ and $\mathrm{G}_{\text {blocker }}(569.8 \pm 6.70 \mathrm{nM})$ than in $\mathrm{G}_{\text {control }}(158.8 \pm 13.09 \mathrm{nM}, \mathrm{p}<$ $0.05)$.

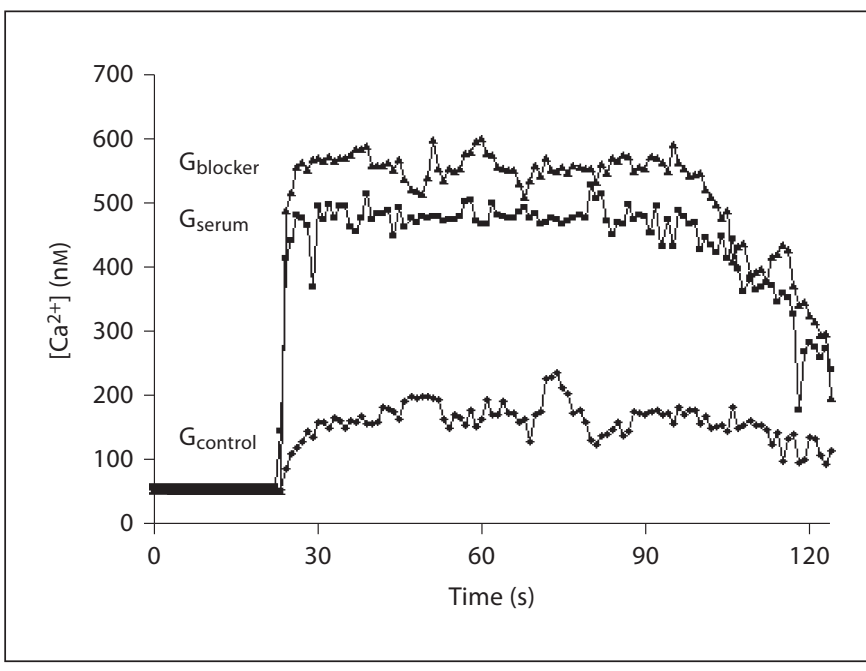

Fig. 9. Effects of serum (obtained from animals subjected to gunshot injury) and GJC blocker on $\left[\mathrm{Ca}^{2+}\right]_{\mathrm{i}}$ increase.

thoracic gunshot wounds by decreasing the initial velocity of a bullet, thereby reducing kinetic energy [14]. In this study, the oxygenation index $\left(\mathrm{PaO}_{2} / \mathrm{FiO}_{2}\right.$, fig. 1$)$ was $<300$ $\mathrm{mm} \mathrm{Hg} \geq 12 \mathrm{~h}$ after shooting, indicating refractory respiratory failure. In addition, diffuse infiltrates were seen bilaterally on the chest radiograph taken $12 \mathrm{~h}$ after gunshot injury. Lung water content and EB leakage rates increased after injury. In order to exclude cardiogenic edema, animals with a pulmonary artery wedge pressure
$>2.6 \mathrm{~mm} \mathrm{Hg}$ were excluded from this study. These findings were consistent with the diagnosis of ALI [23].

As the bullet passes through the lung and transfers its kinetic energy, it produces a pressure wave that creates a temporary cavity which is greater than the bullet's diameter (cavitary effects) [24]. Bellamy and Zajtchuk [25] postulated that the ballistic pressure waves are the main cause for the remote lung injury. Moreover, in our opinion, in addition to lung injury around the ballistic trajectory, gunshot wounds trigger an inflammation cascade involving inflammatory mediators contributing to systemic inflammatory responses and ALI $[26,27]$ following gunshot wounds. Here, serum levels of TNF- $\alpha$ and IL-8 were significantly higher after gunshot injury, i.e., lung inflammation occurred.

Although several therapeutic strategies have been developed clinically, the mortality and morbidity associated with ALI and the acute respiratory distress syndrome (ARDS) remain very high [28]. Increased pulmonary permeability has been recognized as a hallmark of ALI/ ARDS [3]. Thus, modulating pulmonary permeability has become an important strategy to prevent and treat ALI/ARDS. To date, the mechanism inducing increased pulmonary vascular permeability in lung inflammation has not been elucidated yet. Paracellular gap formation has been reported as a factor contributing to the increased pulmonary permeability in lung inflammation [5] and is regulated by competing contractile forces as well as adhesive cell-cell and cell-matrix tethering forces [8]. A key EC contractile event is the phosphorylation of regulatory 
myosin light chains catalyzed by $\mathrm{Ca}^{2+} /$ calmodulin-dependent myosin light chain kinase [5].

In this study, evidence indicated hyperpermeability after gunshot injury, as lung water content and EB leakage increased. Furthermore, immunohistochemistry with $\mathrm{C} x 40$ antibodies showed staining throughout the pulmonary EC membrane. Statistical analysis revealed that a significant negative correlation existed between EB leakage rates and OD values $\left(\rho=-0.934, p<0.05, \rho^{2}=\right.$ 0.8723 ). In an in vitro study in rabbits, serum stimulation increased the clearance of EB-labeled albumin in a timedependent manner but concomitantly decreased the function of GJCs evaluated by scrape-loading and dye transfer studies and expression of $\mathrm{Cx} 40$ in PMVEC. However, pre-incubation with a GJC blocker markedly aggravated these effects. Consequently, Cx40 expression decreased in PMVECs, while scrape-loading and dye transfer studies provided evidence that this serum inhibited GJC function, and this inhibition was aggravated by a GJC blocker. These findings strongly suggest that the increased pulmonary permeability in ALI/ARDS following chest trauma is mediated by cell-cell communication via GJCs, being primarily composed of $\mathrm{Cx} 40$. This decrease in barrier function occurs despite transient cell adhesion due to stimulation of focal adhesion kinase activity and resultant remodeling of the actin cytoskeleton [29].

GJCs provide a pathway for the diffusion of ions and small molecules such as cyclic AMP, cyclic GMP, $\mathrm{Ca}^{2+}$ and inositol triphosphate, and contributes to disease etiology $[9,10,30]$. The function of GJCs is finely regulated by cyclic AMP, inflammatory mediators (e.g. TNF- $\alpha$ and IL-1 $\beta$ ), intracellular $\mathrm{Ca}^{2+}, \mathrm{pH}$, protein phosphorylation and trans-junctional applied voltage [31-35]. In the present study, the decreased function of GJCs led to an overload of intracellular calcium, and this effect was amplified by a GJC blocker, being consistent with the results described by D'hondt et al. [13]. It is believed that a rise in cytosolic calcium concentration causes centripedal contraction of PMVECs [36] resulting in the formation of paracellular gaps.

\section{Conclusions}

In summary, our findings indicate that inflammatory factors, e.g. TNF- $\alpha$ and IL-8, inhibit Cx40 expression, decreasing gap junction function and causing PMVECs to lose intracellular communication, thus leading to intercellular calcium overload and increases in pulmonary vascular permeability. The limitation of this study is that part of the findings were obtained from in vitro studies, which might be different from in vivo studies. Therefore, further studies in vivo on GJC changes are needed to determine GJC as a novel approach for treating ALI after trauma.

\section{References}

1 Wheeler AP, Bernard GR: Acute lung injury and the acute respiratory distress syndrome: a clinical review. Lancet 2007;369:15531564.

-2 Matthay MA, Zimmerman GA: Acute lung injury and the acute respiratory distress syndrome: four decades of inquiry into pathogenesis and rational management. Am J Respir Cell Mol Biol 2005;33:319-327.

$\checkmark 3$ Ware LB, Matthay MA: The acute respiratory distress syndrome. N Engl J Med 2000; 342:1334-1349.

4 Matthay MA, Zimmerman GA, Esmon C, Bhattacharya J, Coller B, Doerschuk CM, Floros J, Gimbrone MA Jr, Hoffman E, Hubmayr RD, Leppert M, Matalon S, Munford R, Parsons P, Slutsky AS, Tracey KJ, Ward P, Gail DB, Harabin AL: Future research directions in acute lung injury: summary of a $\mathrm{Na}$ tional Heart, Lung, and Blood Institute working group. Am J Respir Crit Care Med 2003;167:1027-1035.
5 Dudek SM, Garcia JG: Cytoskeletal regulation of pulmonary vascular permeability. J Appl Physiol 2001;91:1487-1500.

6 Hirata A, Baluk P, Fujiwara T, McDonald DM: Location of focal silver staining at endothelial gaps in inflamed venules examined by scanning electron microscopy. Am J Physiol 1995;269:L403-L418.

-7 Orlova VV, Economopoulou M, Lupu F, Santoso S, Chavakis T: Junctional adhesion molecule- $C$ regulates vascular endothelial permeability by modulating VE-cadherinmediated cell-cell contacts. J Exp Med 2006; 203:2703-2714.

-8 Garcia JG, Schaphorst KL: Regulation of endothelial cell gap formation and paracellular permeability. J Investig Med 1995;43:117126.

9 Mese G, Richard G, White TW: Gap junctions: basic structure and function. J Invest Dermatol 2007;127:2516-2524.
10 Vinken M, Vanhaecke T, Papeleu P, Snykers S, Henkens T, Rogiers V: Connexins and their channels in cell growth and cell death. Cell Signal 2006; 18:592-600.

-11 Isakson BE, Duling BR: Heterocellular contact at the myoendothelial junction influences gap junction organization. Circ Res 2005;97:44-51.

12 De WC, Hoepfl B, Wolfle SE: Endothelial mediators and communication through vascular gap junctions. Biol Chem 2006;387:39.

13 D'hondt C, Ponsaerts R, Srinivas SP, Vereecke J, Himpens B: Thrombin inhibits intercellular calcium wave propagation in corneal endothelial cells by modulation of hemichannels and gap junctions. Invest Ophthalmol Vis Sci 2007;48:120-133.

14 Guo J, Liu W, Liu Y, Cai J, Li B, Li S, Wang D, Zhang LC: Parameters and establishment of firearm thoracic wounds in a rabbit model (in Chinese). J Fourth Mil Med Univ 2000; 21:527-529. 
15 Karaiskos Th, Papaloes A, Tomos P, Papacharalambous A, Lioulias A: Pulmonary artery catheterization in rabbits: our experience. Pneumon 2006;19:46-48.

16 Miller DL, Roberts AM: Pulmonary artery occlusion and reperfusion causes microvascular constriction in the rabbit lung. Ann Thorac Surg 1999;67:323- 328.

-17 Stevens T, Creighton J, Thompson WJ: Control of cAMP in lung endothelial cell phenotypes. Implications for control of barrier function. Am J Physiol 1999;277:L119L126.

-18 Patterson CE, Rhoades RA, Garcia JG: Evans blue dye as a marker of albumin clearance in cultured endothelial monolayer and isolated lung. J Appl Physiol 1992;72:865-873.

-19 Aoki Y, Maeno T, Aoyagi K, Ueno M, Aoki F, Aoki N, Nakagawa J, Sando Y, Shimizu Y, Suga T, Arai M, Kurabayashi M: Pioglitazone, a peroxisome proliferator-activated receptor gamma ligand, suppresses bleomycin-induced acute lung injury and fibrosis. Respiration 2009;77:311-319.

-20 Traeger T, Kessler W, Hilpert A, Mikulcak M, Entleutner M, Koerner P, Westerholt A, Cziupka K, Rooijen N, Heidecke CD, Maier S: Selective depletion of alveolar macrophages in polymicrobial sepsis increases lung injury, bacterial load and mortality but does not affect cytokine release. Respiration 2009;77:203-213.

-21 Oktem S, Ersu R, Uyan ZS, Cakir E, Karakoc F, Karadag B, Kiyan G, Dagli E: Home ventilation for children with chronic respiratory failure in Istanbul. Respiration 2008;76:7681.
22 Treggiari MM, Hudson LD, Martin DP, Weiss NS, Caldwell E, Rubenfeld G: Effect of acute lung injury and acute respiratory distress syndrome on outcome in critically ill trauma patients. Crit Care Med 2004;32: 327-331.

23 Bernard GR, Artigas A, Brigham KL, Carlet J, Falke K, Hudson L, et al: The AmericanEuropean Consensus Conference on ARDS. Definitions, mechanisms, relevant outcomes, and clinical trial coordination. Am J Respir Crit Care Med 1994;149:818-824.

24 Fackler ML: Wound ballistics. A review of common misconceptions. JAMA 1988;259: 2730-2736.

25 Bellamy RF, Zajtchuk R (eds): Conventional Warfare: Ballistic, Blast and Burn Injuries. Textbook of Military Medicine. Washington, Office of the Surgeon General, 1990

26 American College of Chest Physicians/Society of Critical Care Medicine Consensus Conference: Definitions for sepsis and organ failure and guidelines for the use of innovative therapies in sepsis. Crit Care Med 1992; 20:864-874.

27 Kim DJ, Park SH, Sheen MR, Jeon US, Kim SW, Koh ES, Woo SK: Comparison of experimental lung injury from acute renal failure with injury due to sepsis. Respiration 2006 73:815-824

28 Ning Q, Wang X: Response of alveolar type II epithelial cells to mechanical stretch and lipopolysaccharide. Respiration 2007;74: 579-585.

29 Mehta D, Tiruppathi C, Sandoval R, Minshall RD, Holinstat M, Malik AB: Modulatory role of focal adhesion kinase in regulating human pulmonary arterial endothelial barrier function. J Physiol 2002;539:779-789.
30 Christ GJ, Moreno AP, Melman A, Spray DC: Gap junction-mediated intercellular diffusion of $\mathrm{Ca}^{2+}$ in cultured human corporal smooth muscle cells. Am J Physiol 1992;263: C373-C383.

-31 Figueroa XF, Alvina K, Martinez AD, Garcés G, Rosemblatt M, Boric MP, Sáez JC: Histamine reduces gap junctional communication of human tonsil high endothelial cells in culture. Microvasc Res 2004;68:247-257.

32 Lidington D, Tyml K, Ouellette Y: Lipopolysaccharide-induced reductions in cellular coupling correlate with tyrosine phosphorylation of connexin 43. J Cell Physiol 2002; 193:373-379.

33 Saez JC, Berthoud VM, Branes MC, Martinez AD, Beyer EC: Plasma membrane channels formed by connexins: their regulation and functions. Physiol Rev 2003;83:13591400 .

34 Simon AM, McWhorter AR, Chen H, Jackson CL, Ouellette Y: Decreased intercellular communication and connexin expression in mouse aortic endothelium during lipopolysaccharide-induced inflammation. J Vasc Res 2004;41:323-333.

35 Tonon R, D’Andrea P: The functional expression of connexin 43 in articular chondrocytes is increased by interleukin $1 \beta$ : evidence for a $\mathrm{Ca}^{2+}$-dependent mechanism. Biorheology 2002;39:153-160.

$36 \mathrm{Ng}$ LC, Gurney AM: Store-operated channels mediate $\mathrm{Ca}^{2+}$ influx and contraction in rat pulmonary artery. Circ Res 2001;89:923929. 